Olde Hartman, T.C., Rijswijk, E. van, Dulmen, S. van, Weel-Baumgarten, E. van, Lucassen, P.L.B.J., Weel, C. van. How patients and family physicians communicate about persistent medically unexplained symptoms: a qualitative study of video-recorded consultations. Patient Education and Counseling: 2013, 90(30), 354-360

\begin{tabular}{|l|l|}
\hline Postprint Version & 1.0 \\
\hline Journal website & http://www.pec-journal.com/article/S0738-3991(11)00126-1/abstract \\
\hline Pubmed link & http://www.ncbi.nlm.nih.gov/pubmed/21482059 \\
\hline DOI & $10.1016 /$ j.pec.2011.02.014 \\
\hline
\end{tabular}

This is a NIVEL certified Post Print, more info at http://www.nivel.eu .

\title{
How patients and family physicians communicate about persistent medically unexplained symptoms. A qualitative study of video-recorded consultations
}

\author{
TiM C. OLDE HARTMAN ${ }^{\mathrm{A}}$, ERIC VAN RIJSWIJK ${ }^{\mathrm{A}}$, SANDRA VAN DULMEN ${ }^{\mathrm{B}}$, EVELYN VAN WEEL- \\ BAUMGARTEN $^{\mathrm{A}}$, PETER L.B.J. LUCASSEN ${ }^{\mathrm{A}}$, CHRIS VAN WEEL ${ }^{\mathrm{A}}$ \\ ${ }^{a}$ Department of Primary and Community Care, Radboud University Nijmegen Medical Centre, Nijmegen, \\ The Netherlands \\ ${ }^{\mathrm{b}}$ NIVEL (Netherlands Institute for Health Services Research), Utrecht, The Netherlands
}

\section{ABstract}

Objective: To study doctor-patient interaction styles in consultations with patients presenting persistent medically unexplained symptoms (MUS) and to study on which stages of the consultation patients and doctors focus within the available time.

Methods: exploratory, qualitative analysis of transcripts of 20 videotaped consultations between family physicians (FP) and persistent MUS patients.

Results Patients presented many symptoms in a rather unstructured way. However, FPs hardly used structuring techniques such as agenda setting and summarizing. Patients with persistent MUS got much opportunity to tell their story, but the reasons for encounter, their beliefs and concerns were not discussed in a structured manner. Although consultations were focused on these issues, mostly patients themselves initiated discussion of their ideas, concerns and expectations. FPs' extensive explanations of the origin of the symptoms often did not take patients' beliefs and concerns into account.

Conclusions: Due to patients' multiple symptom presentation and the absence of FPs' structuring techniques, consultations of persistent MUS patients proceed rather unfocused. However, patients got ample opportunity to tell their story.

Practice implications: Persistent MUS patients might benefit from structured consultations focused on the exploration of the reason for encounter.

\section{INTRODUCTION}

Patients complaining of physical symptoms in the absence of physical disease are common in primary care. These symptoms are often described as medically unexplained symptoms (MUS) [1] and [2]. In patients with MUS, symptoms or impairment improve when consultations meet the patients' expectations or when patients feel understood [3]. Recently, two studies showed that physicians' communication during the initial presentation of MUS is hampered [4] and [5]. Epstein et al. concluded that physicians face lack of time and do not explore and validate the MUS patient's reason for visit, their ideas, expectations and concerns [4]. Kappen and van Dulmen concluded that family physicians (FPs) explore patients' concerns mainly medically [5]. Despite these physicians' communication barriers during the initial presentation of MUS [6], only a minority (2.5\%) of the patients will evolve into a chronic disabling condition of persistent MUS [7]. From this moment communication is often the only tool FPs have in handling these patients 
Olde Hartman, T.C., Rijswijk, E. van, Dulmen, S. van, Weel-Baumgarten, E. van, Lucassen, P.L.B.J., Weel, C. van. How patients and family physicians communicate about persistent medically unexplained symptoms: a qualitative study of video-recorded consultations. Patient Education and Counseling: 2013, 90(30), 354-360

[4] and [8]. However, doctor-patient interaction styles in consultations with patients with persistent MUS have not been well studied, and may bring important insights to improve the quality of care of these patients.

Consultations between doctors and persistent MUS patients are not straightforward but can be considered as complex consultations [9]. As symptoms are medically unexplained, the link between cause and symptom is unclear, and FPs are uncertain about the way forward [10]. Persistent MUS patients are aware of the complex nature of their problems [11], [12] and [13]. They have to present complex and multifaceted reasons for consulting, discuss concerns about the symptoms and problems, and choose whether or not to present emotional aspects of their problems, in a 10-15 min consultation [13], [14] and [15]. It is understandable that both patients and FPs report insufficient time to deal effectively with persistent MUS during consultations [16] and [17]. However, it is still not clear how patients and FPs reach their goals during the consultations and on which stages in the consultation they focus.

Therefore, the aim of this study is to analyze (1) how patients present and how FPs explore the patients' symptoms and problems during consultations and (2) on which stages of the consultation they focus within the available time.

\section{METHODS}

\subsection{Data source: Dutch National Survey of General Practice}

Data for the present study were drawn from the Second Dutch National Survey in General Practice (DNSGP-2) [18]. This survey is a large-scale research project carried out in the Netherlands between May 2000 and April 2002 and studied a representative sample of 104 family practices with 195 FPs and 399,068 listed patients. The survey comprised an epidemiologic study about the work of FPs and a video observation study of consultations in which each participating FP consented to video tape approximately 20 clinical encounters on two arbitrary days. A total of 142 FPs (72.8\%) agreed to participate in the video observation study [19]. Prior to the consultation, a research assistant informed the patients and asked informed consent about the video observation. A total of 2784 patients participated in the video-observation study, 377 patients (11.9\%) refused. Before and after the videotaped encounter patients completed a questionnaire about sociodemographic characteristics, presented symptoms and general health status. Immediately after the consultation, FPs completed a questionnaire with items on characteristics of the FP, questions about how familiar the FP was with the patient and how the FP valued the psychosocial and work related aspects of the presented symptoms. Furthermore, FPs rated on a 5-point Likert-type scale (extremes labeled as 'not at all' and 'very much') whether they believed psychosocial factors played a role in the problem presented during the consultation. FPs coded patients' symptoms and diagnoses according to the International Classification in Primary Care (ICPC) system [20] and [21].

\subsection{Selection of patients with medically unexplained symptoms}

We selected from the video-observation study all videotaped consultations in which medically unexplained symptoms were the main subject of the encounter. Inclusion criteria were: (1) patients consulting their own FP, (2) consultations for physical symptoms for which the patient had consulted the FP before and in which, according to the FP, the symptoms were related to psychosocial factors ('much'/'very much' on 5-point Likert-type scale), (3) age of the patient $\geq 18$ years and (4) no psychiatric diagnosis and/or social diagnosis according to the ICPC during this consultation. Exclusion criteria were: bad sound-quality and consultations by one of the authors. When more than one video consultation of a FP appeared in our selection, only the first consultation was included. Two independent researchers (ToH and SvD or EvR) looked at the video recordings and established whether medically unexplained symptoms were the main topic. Encounters were included in the final sample when both researchers agreed. In case of disagreement, we excluded the consultation. We used Cohen's kappa statistic ( $\kappa)$ to assess agreement between the two researchers [22].

\subsection{Data analysis}

Data analysis started using qualitative methods to develop a coding scheme of FPs' exploration of the patients' symptoms and problems [23]. The theoretical framework guiding the analysis was the broad concept of the biopsychosocial model [24]. This model proposes illness to be viewed as a result of interacting mechanisms at the biomedical, interpersonal and environmental levels. The model is widely 
Olde Hartman, T.C., Rijswijk, E. van, Dulmen, S. van, Weel-Baumgarten, E. van, Lucassen, P.L.B.J., Weel, C. van. How patients and family physicians communicate about persistent medically unexplained symptoms: a qualitative study of video-recorded consultations. Patient Education and Counseling: 2013, 90(30), 354-360

used in primary care consultations. Using this model in consultations implies that patients' symptoms, illness beliefs, anxiety, concerns, illness behavior and social environment are addressed [25].

The included videotaped consultations were completely and anonymously verbatim transcribed and entered into Atlas.ti. The qualitative analyses were executed with this software program, a package for detailed coding in qualitative data analysis.

We analyzed the transcripts using the principles of constant comparative analysis [26]. During this analysis transcripts are subsequently thematically coded. The main aim of this analysis is to organize utterances by theme and to explore similarities and differences between consultations.

Two researchers (ToH, EvR) read all transcripts several times to familiarize themselves with the data. They independently made a first categorization by applying codes to meaningful words and sentences in the transcripts. These codes were discussed and refined during consensus meetings. When additional codes emerged these were discussed and applied to the transcripts. Concepts and categories emerged through this iterative process of coding, analysis and discussion. Codes appearing from the utterances of the participants in the consultations are presented in Table 1. During the iterative process of qualitative analysis we noticed the complex structure of the consultations. To gain a better understanding of this complex structure we decided to code the stages of the consultation, apart from the utterances of the participants during the consultation. These stages were derived from the Dutch FPs' communication skills training program [15], [27] and [28] (Table 2). After 8 videotaped consultations, the first results of the analysis were discussed with a senior researcher (PL). Data collection continued until no significant new themes emerged (saturation) [29]. This was achieved after 15 consultations. To quantify on which stages of the consultation patients and FPs focus within the available time of the consultation. We calculated, as a proxy, the percentage of text in the transcript (the number of text lines of a particular stage of the consultation divided by the total number of text lines of the consultation) spent on each of the different stages.

\section{[TABLE 1][TABLE 2]}

\subsection{Ethical approval}

The study was carried out according to Dutch privacy legislation rules. The privacy regulation was approved by the Dutch Data Protection Authority.

\section{RESULTS}

\subsection{Sample characteristics}

The total number of video consultations in the Second Dutch National Survey of General Practice (DNSGP2) was 2784. Fifty nine of these video consultations met our inclusion criteria and were screened by one of the authors (ToH). In 14 cases more than one video consultation of a FP appeared in the selection, 4 video consultations had a bad sound quality and in 1 video consultation one of the authors (PL) was the FP. These 19 video consultations were excluded. Therefore, a total of 40 video consultations could be included for screening by two independent researchers (ToH and SvD or EvR). Because MUS was not the main topic of the consultation in 20 of these video consultations, a total of 20 video consultations could be included for further analysis (Fig. 1). The interobserver agreement for inclusion was $\kappa=0.79$ (95\%-CI: 0.59-0.99). We considered this level of agreement to be 'good'.

\section{[FIGURE 1]}

Eight (40\%) of the patients involved in the final video consultation sample were men, aged between 25 and 80 (mean $=47$ ) years. The 20 FPs consisted of $15(75 \%)$ men, aged from 34 to 61 (mean $=45)$ years with an average of 15.7 (range 3-30) years of FP working experience. Mean (and median) duration of consultation was 13.5 (12.1) min; ranging from 8.1 to $37.0 \mathrm{~min}$.

Within the available time of the consultation, patients and doctors focus most on the story of the patient, discussion and exploration of patients' beliefs and concerns, and on explaining the symptoms (respectively 21.8, 18.7 and $16.8 \%$ of the total amount of text is spent on these stages) (Table 3). Agenda setting, summarizing and evaluation of the consultation was limited. 
Olde Hartman, T.C., Rijswijk, E. van, Dulmen, S. van, Weel-Baumgarten, E. van, Lucassen, P.L.B.J., Weel, C. van. How patients and family physicians communicate about persistent medically unexplained symptoms: a qualitative study of video-recorded consultations. Patient Education and Counseling: 2013, 90(30))), 354-360

\section{[TABLE 3]}

\subsection{Patients' symptom presentation}

Most (95\%) persistent MUS patients presented more than one symptom. Three quarters of the patients presented medically unexplained symptoms as well as medically explained symptoms. The average number of symptoms presented was 3.6 (range 1-5). The average number of MUS presented was 2.4 (range 1-5). The most common symptoms were musculoskeletal $(n=15)$, gastrointestinal $(n=8)$ and general and unspecified symptoms ( $n=11$ ), such as feeling ill, weakness/tiredness, sweating or swelling.

Persistent MUS patients presented multiple symptoms and seemed to switch from one symptom to another during all stages of the consultation.

They often started to discuss new symptoms and concerns after the FP finished history taking, physical examination and explanation (Quotation 1).

Quotation 1 (P11 116-2;023-111)

[Patient's story, symptom 1]*

P: It's either painful gas or it's a lot of pain in my belly. And my bowel movements happen or don't happen but they look kind of weird. But it will go away. It's always gone away eventually.

D: Okay, so you have had these complaints for years.

[Medical exploration]

D: Abnormal bowel movements. No blood or mucus?

P: No. No.

D: Firm and pulpy, no diarrhea?

P: No, I don't have that.

[No physical examination]

[Explanation]

D: Okay, it seems to me that you have irritable bowel syndrome - sensitive intestines - and that can cause cramps. About $20 \%$ of the population has this kind of bowel problem to some extent. It's not malignant and there is no infection. It's just that the intestines don't function optimally. And so it's important that you get enough fiber and that you take the powders (movicolon).

[Patient's story, symptom 2]

P: And the itch. It won't go away and it's awful.

D: So, we have to deal with the itch.

P: Yes, it's ridiculous but it's sometimes really bad on my face and on my back, it's the worst - it's always the same place. I've had it for a really long time.

*The words between brackets represent the codes given by the researchers and used in the constant comparative analysis.

\subsection{PATIENTS' ATTEMPTS TO ADDRESS THEIR NEEDS}

In most encounters, the patients' reason for seeking help remained unclear. Although clarifying the reason for encounter (RFE) is an important task for the FP in order to reach a more focused communication, in 13 consultations (65\%) there was no exploration of the reason for encounter at all. The absence of FPs' exploration of the reason for encounter might be the reason why patients themselves try to initiate such a discussion. It appeared from the data that during consultations in which the reason for encounter was discussed $(n=7)$, most of the time the patients themselves initiated talking about this subject $(n=5)$

(Quotation 2). Only in two consultations the doctor initiated the discussion on the reason for encounter. Discussions on the reason for encounter took 2.7\% (range 0-15.7) of the text in the transcripts (Table 3 ). Quotation 2 (P8 C10208;24-31)

P: And when I go to bed, I feel very restless. I have these heart palpitations.

D: Yes,

P: So I was wondering - I read about something called beta-blockers. I don't know if that applies to my situation but -

D: Hmm

P: Someone told me about propanolol. I was wondering if that was something for me.

D: Yeah, okay.

In all but two video consultations patients started talking about their beliefs and concerns. However, in the two encounters in which no discussion on beliefs and concerns took place, the patient tried to initiate such a 
Olde Hartman, T.C., Rijswijk, E. van, Dulmen, S. van, Weel-Baumgarten, E. van, Lucassen, P.L.B.J., Weel, C. van. How patients and family physicians communicate about persistent medically unexplained symptoms: a qualitative study of video-recorded consultations. Patient Education and Counseling: 2013, 90(30), 354-360

discussion but the FP refrained from responding (Quotation 3). In the encounters in which beliefs and concerns were discussed, patients mostly initiated such a discussion: in 16 consultations (89\%) patients made attempts to initiate discussion, whereas in 9 consultations (50\%) FPs did. This is also reflected in the amount of text spent in the transcripts of the consultations on this topic. The total amount of text spent in the transcripts regarding discussing patients' beliefs and concerns initiated by the patient or by the FP is $13.9 \%$ (range $0-40.1$ ), respectively $4.8 \%$ (range $0-17.8$ ) (Table $3^{\text {T). }}$.

It is noteworthy that in the majority of the consultations (10 out of 18) in which patients' beliefs and concerns were discussed, discussion of these beliefs and concerns only took place for a limited number of symptoms presented during the consultation.

Quotation 3 (P1 C2601;132-40)

P: It's not good at all. I feel myself going so unbelievably downhill.

D: This is something you need to discuss with a neurologist. You can make an appointment with one. I'll write a referral letter and you can pick that up at my assistant's desk. But your legs: that's also an issue for you?

P: Yes, I know I have a lot of weight to carry but, oh my, that's not easy. It's like something is broken in my brain. I think every time, 'I have to lose weight, I have to lose weight,' and, at the very same moment, I stuff myself. It just doesn’t work that way up here (P points to head).

D: You need to lose weight but you eat too.

The consequences of the symptoms on patients' daily activities, social environment and illness behavior was less well discussed. In 9 consultations (45\%) there was no discussion of these themes at all. Again, most of the time discussion of these consequences of the symptoms was initiated by the patients namely in 7 consultations; in one consultation this discussion was initiated by the FP as well as the patient and in three consultations the FP initiated the discussion (Quotation 4). Almost 3\% (2.7; range 0-12.3) of the total amount of text in the transcripts of the consultations spent on talking about the consequences of the symptoms on daily activities, social environment and illness behavior was initiated by the patient against $1.1 \%$ (range $0-7.4$ ) initiated by the FP (see ${ }^{\text {Table } 3}$ ).

Quotation 4 (P2 C070-13;34-45)

D: How are you sleeping?

P: At night, I sleep okay now, but during the day, I try not to spend time in bed. It's nice to know that I can go to bed but then I restrain myself with, 'No, I can't stay in bed all day.' And then I try to do some stuff around the house - the dishes, vacuuming, dusting.

D: So you do that?

P: And then I try to sleep at night. And when I wake up in the morning, I have those puffy eyes. And those chewable pills, I don't take them one after another anymore. Or should I keep taking them? Because sometimes I still have - especially when I have to bend over, I still see stars.

D: But you eat well?

$\mathrm{P}$ : Yes, if I know that I need some kind of feeling or is that not necessary?

In nearly all consultations there was much opportunity for explanation of the symptoms. The total amount of text in the transcripts about explanations is $16.8 \%$ (range $0-52.9$ ) $\left({ }^{\text {Table } 3}\right.$ ). Although almost one fifth of the text in the transcripts was spent on explaining the symptoms, patients responded on FP explanations with new remarks about their symptoms, beliefs and concerns.

Furthermore, most of the time, explanations given by the FPs did not incorporate beliefs and concerns that patients presented during the consultation. Moreover, FPs attempts to reassure patients were often not focused on the patients' concerns (Quotation 5).

Quotation 5 (P4 C077-04:4-9;21-6;80-5;109-11)

(Patient concerns)

P: I'm having problems with my throat, esophagus again. I feel it when I am doing exercise. It doesn't have anything to do with my heart, does it? I have it every time I roll over at night.

D: Yes

P: I don't know but I think that it's lower. It's like something is stuck there.

(Reason for encounter and patient concerns)

P: I've also had chest pains so I wanted to ask if you would be willing to take a look. I'm a little concerned. I'd just like to know for sure that there's nothing going on.

D: If we know that it's your throat and not your heart, then that's good. 
Olde Hartman, T.C., Rijswijk, E. van, Dulmen, S. van, Weel-Baumgarten, E. van, Lucassen, P.L.B.J., Weel, C. van. How patients and family physicians communicate about persistent medically unexplained symptoms: a qualitative study of video-recorded consultations. Patient Education and Counseling: 2013, 90(30), 354-360

P: Yes.

(Explanation)

P: I was also really busy earlier this week. I've been feeling kind of hurried the last little while so I took a seresta pill and the pain in my throat went away.

D: Yes, that could mean that the tension that you feel inside is coming out through your throat, like your throat is literally being choked.

P: Yes, I do have that kind of feeling

(Patient response)

P: But my heart has nothing to do with it?

D: No, your heart has nothing to do with it.

\subsection{FPs' structuring behavior}

In the video consultations, FPs gave patients with persistent MUS much opportunity to tell their story (21.8\% (range 5.1-80.7) of the text in the transcripts). However, FPs did not do an in-depth inquiry of the symptoms (7.9\% (range $0-39.4$ ) of the text in the transcripts). In $50 \%$ of the consultations $(n=10)$ there was no in-depth inquiry of the presented symptoms at all. In half of the consultations in which an in-depth inquiry of the symptoms was performed, the FP did not explore all medically unexplained symptoms presented during that consultation. Furthermore, it appeared from the video consultations that FPs hardly use structuring techniques, such as agenda setting, announcing and performing physical examination and summarizing the information obtained during the consultation. Agenda setting was explicitly performed in one consultation. Physical examination was performed in eight consultations and a summary was given in only one consultation.

\section{DISCUSSION AND CONCLUSION}

\subsection{Discussion}

Our findings of the difficulties of discussing the reason for encounter and patients' beliefs and concerns regarding the symptoms during the persistent MUS consultations are in line with the findings of Epstein et al. [4]. Furthermore, it is known from direct observation of patients' presentations of MUS that almost all patients provide opportunities for FPs to address psychosocial issues, psychosocial concerns [5] and [30]. Our study adds rigor to these findings as we studied doctor-patient communication in persistent MUS consultations. Our results indicate that doctor-patient communication can be improved by focusing on the exploration of patients' beliefs and concerns and incorporating these into FPs' explanatory and reassuring strategies. These findings are important as discussion of patient's ideas and concerns, shared understanding and clarifying the reason for encounter contribute to a more satisfactory consultation according to patients [31].

The observations of our study confirm that the chaotic structure of most MUS consultations reflect the chaotic narrative of the people who live with MUS [32]. Nettleton highlighted that the narratives of MUS patients shared many features of chaos narratives [33]. These narratives are characterized by confusion and uncertainty in the absence of a diagnosis and prognosis [32]. Moreover, these narratives are difficult to 'listen' to and difficult to 'hear', because it reminds us of our own vulnerability and limitations [34]. This might explain why FPs have difficulties in structuring the persistent MUS consultations and why patients present multiple symptoms in a rather unstructured way. Although giving patients time for their story is an important element of working patient-centered, persistent MUS patients might benefit from more focused patient-centered interaction style in which FPs structure the consultation and explore needs, concerns and beliefs. The ample opportunity patients get to tell their story and present their symptoms possibly reflect FPs' commitment with these patients which is in line with research on FPs perceptions about patients with persistent MUS [10]. However, this commitment is worth to yield more effect.

This is the first study in patients with heterogeneous undifferentiated persistent MUS using consultations between doctor and MUS patients in which neither the doctor, nor the patient was aware of the subject of study. Doctor-patient communication studied in this way represents daily practice reality. Furthermore, FPs and patients in these consultations already built a doctor-patient relationship as they knew each other for a long time and had discussed the symptoms before. However, in most cases, a single consultation is not the beginning or the end of the story. Each new consultation carries over memories of previous ones, which might have influenced the videotaped consultations [35]. This might explain why we found limited medical 
Olde Hartman, T.C., Rijswijk, E. van, Dulmen, S. van, Weel-Baumgarten, E. van, Lucassen, P.L.B.J., Weel, C. van. How patients and family physicians communicate about persistent medically unexplained symptoms: a qualitative study of video-recorded consultations. Patient Education and Counseling: 2013, 90(30), 354-360

exploration of the presented symptoms and no physical examination in most consultations. However, we did not find utterances referring to the content of previous consultations on the symptoms presented.

Video-recording has been recommended as the best method for researching doctor-patient communication during consultations [36]. According to Coleman, there is little evidence that video-recording influences the behavior of either the FPs or patients (i.e. Hawthorne effect), but it may cause bias in the characteristics of doctors and patients who agree to participate [37]. However, with a response rate of $89 \%$ in the DNSFP-2 and the attendance of a representative sample of family practices in The Netherlands, participation bias in our study will be limited. Furthermore, we found 2.1\% (59 out of 2784) of the total number of video consultations in the DNSGP-2 concerned consultations with patients with persistent MUS. This is in line with the findings of Verhaak et al. that $2.5 \%$ of the patients in primary care present with persistent MUS [7].

By quantifying on which stages of the consultation patients and FPs focus within the available time of the consultation, we studied the doctor-patient communication in persistent MUS consultations on different levels which improved our understanding of the role of the doctor-patient communication [23] and [38]. We chose to quantify as measure of focus the number of text lines. We decided to this approach as it had in our view, face validity, but it is important to formally validate it in further study. Besides, we do realize that the FP's and patient's speaking rate, the duration of silences within the consultation and other non-verbal characteristics can make the number of text lines as a proxy of speech focus less reliable. As our goal was not to study doctor-patient interaction on micro level, we choose not to use conversation analysis techniques [39].

The small sample size and the cross sectional nature of the qualitative analysis preclude definitive conclusions. Our findings should be confirmed in a larger, prospective qualitative study that could track doctor-patient communication regarding the unexplained symptoms over time.

\subsection{Conclusion}

Patients' showed a rather unfocused and fragmented presentation of multiple symptoms during all stages of the persistent MUS consultation. However, ways of giving structure to the consultation such as agenda setting and summarizing were hardly ever used by the FPs. Patients had ample opportunity to tell their story, but the reason for encounter, patients' beliefs and concerns were not discussed in a structured manner. Mostly, patients themselves initiated discussion on the reason for encounter, their beliefs and concerns and the consequences on daily activities, social environment and illness behavior. Furthermore, the extensive explanation of the origin of the symptoms they received from their FP was often not focused on their beliefs and concerns.

Although consultations with persistent MUS patients seemed quite patient-centered as patients have much opportunity for telling their story, patients might benefit more from a structured consultation focused on the exploration of their ideas, concerns and expectations.

\subsection{Practice implication}

Exploration and validation of patients' experiences of illness, patients' distress and patients' concerns and incorporating these items into explanations and reassurance may improve the care of patients with persistent MUS.

Educational interventions in graduate and advanced professional training, aiming at enhancing a systematic symptom exploration and reason for encounter, improving FPs symptom explanation and reassurance during the persistent MUS consultation should be developed and might result in a more focused patient-centered approach which can enhance the wellbeing of patients with MUS.

\section{Conflict of interest}

None.

\section{Authors contributions}

All authors participated in the research process; ToH, PL, SvD, CvW were responsible for study design; ToH, SvD, EvR collected the data; ToH, EvR, PL, SvD, EvW, CvW performed data analysis and interpretation; ToH, EvR and PL drafted the manuscript and all authors helped with revisions to the manuscript. All authors approved the final version. 
Olde Hartman, T.C., Rijswijk, E. van, Dulmen, S. van, Weel-Baumgarten, E. van, Lucassen, P.L.B.J., Weel, C. van. How patients and family physicians communicate about persistent medically unexplained symptoms: a qualitative study of video-recorded consultations. Patient Education and Counseling: 2013, 90(30) )), 354-360

\section{Acknowledgments}

The Second Dutch National Survey of General Practice was funded by the Ministry of Health, Welfare and Sports. The authors are grateful for the efforts of the family practices, the patients and the research staff of the DNSGP-2.

\section{REFERENCES}

[1] Kroenke K, Mangelsdorff AD. Common symptoms in ambulatory care: inci- dence, evaluation, therapy, and outcome. Am J Med 1989;86:262-6.

[2] Bridges KW, Goldberg DP. Somatic presentation of DSM III psychiatric dis- orders in primary care. J Psychosom Res 1985;29:563-9.

[3] Downes-Grainger E, Morriss R, Gask L, Faragher B. Clinical factors associated with short-term changes in outcome of patients with somatized mental disorder in primary care. Psychol Med 1998;28:703-11.

[4] Epstein RM, Shields CG, Meldrum SC, Fiscella K, Carroll J, Carney PA, et al. Physicians' responses to patients' medically unexplained symptoms. Psycho- som Med 2006;68:269-76.

[5] Kappen T, van Dulmen S. General practitioners' responses to the initial presentation of medically unexplained symptoms: a quantitative analysis. Biopsychosoc Med 2008;2:22.

[6] olde Hartman TC, Borghuis MS, Lucassen PL, van de Laar FA, Speckens AE, van WC. Medically unexplained symptoms, somatisation disorder and hypochon- driasis: course and prognosis. A systematic review. J Psychosom Res 2009;66:363-77.

[7] Verhaak PF, Meijer SA, Visser AP, Wolters G. Persistent presentation of medi- cally unexplained symptoms in general practice. Fam Pract 2006;23:414-20.

[8] Ring A, Dowrick CF, Humphris GM, Davies J, Salmon P. The somatising effect of clinical consultation: what patients and doctors say and do not say when patients present medically unexplained physical symptoms. Soc Sci Med 2005;61:1505-15.

[9] Innes AD, Campion PD, Griffiths FE. Complex consultations and the 'edge of chaos'. Br J Gen Pract 2005;55:47-52.

[10] olde Hartman TC, Hassink-Franke LJ, Lucassen PL, van Spaendonck KP, van WC. Explanation and relations. How do general practitioners deal with patients with persistent medically unexplained symptoms: a focus group study. BMC Fam Pract 2009;10:68.

[11] olde Hartman TC, Lucassen PLBJ, van de Lisdonk EH, Bor JHJ, van Weel C. Chronic functional somatic symptoms: a single syndrome? Br J Gen Pract 2005.

[12] Escobar JI, Waitzkin H, Silver RC, Gara M, Holman A. Abridged somatization: a study in primary care. Psychosom Med 1998;60:466-72.

[13] Peters S, Rogers A, Salmon P, Gask L, Dowrick C, Towey M, et al. What do patients choose to tell their doctors? Qualitative analysis of potential barriers to reattributing medically unexplained symptoms. J Gen Intern Med 2009;24:443-9.

[14] Stuarts M, Lieberman J. The fifteen minute hour: therapeutic talk in primary care. Abingdon: Radcliffe Publishing Ltd.; 2008.

[15] van Dalen J, Prince CJ, Scherpbier AJ, van der Vleuten CP. Evaluating commu- nication skills. Adv Health Sci Educ Theory Pract 1998;3:187-95.

[16] Dowrick C, Gask L, Hughes JG, Charles-Jones H, Hogg JA, Peters S, et al. General practitioners' views on reattribution for patients with medically unexplained symptoms: a questionnaire and qualitative study. BMC Fam Pract 2008;9:46.

[17] Peters S, Stanley I, Rose M, Salmon P. Patients with medically unexplained symptoms: sources of patients' authority and implications for demands on medical care. Soc Sci Med 1998;46:559-65.

[18] Westert G, Jabaaij L, Schellevis F. Morbidity, performance and quality in primary care. Dutch general practice on stage. Oxford: Radcliff Publishing; 2006.

[19] van den Brink-Muinen A, van Dulmen S, de Haes HC, Visser AP, Schellevis FG, Bensing JM. Has patients' involvement in the decision-making process chan- ged over time? Health Expect 2006;9:333-42.

[20] Lamberts H, Hofmans-Okkes I. Episode of care: a core concept in family practice. J Fam Pract 1996;42:161-9.

[21] WONCA International Classification Committee. ICPC-2: international classi- fication of primary care,

2nd ed., Oxford: Oxford University Press; 1998.

[22] Cohen J. A coefficient of agreement for nominal scales. Educ Psychol Meas 1960;20:37-46.

[23] Pope C, Ziebland S, Mays N. Qualitative research in health care. Analysing qualitative data. Brit Med J 2000;320:114-6.

[24] Engel GL. The need for a new medical model: a challenge for biomedicine. Science 1977;196:129-36. 
Olde Hartman, T.C., Rijswijk, E. van, Dulmen, S. van, Weel-Baumgarten, E. van, Lucassen, P.L.B.J., Weel, C. van. How patients and family physicians communicate about persistent medically unexplained symptoms: a qualitative study of video-recorded consultations. Patient Education and Counseling: 2013, 90(30) ) )), 354-360

[25] Metz JCM, Verbeek-Weel AMM, Huisjes HJ. Raamplan 2001 artsenopleiding; bijgestelde eindtermen van de artsopleiding. Nijmegen: Mediagroep Nijme- gen; 2001.

[26] Glaser BG, Strauss AL. The discovery of grounded theory. Chigago: Aldine; 1967.

[27] Ram P, Grol R, Rethans JJ, Schouten B, Van d V, Kester A. Assessment of general practitioners by video observation of communicative and medical perfor- mance in daily practice: issues of validity, reliability and feasibility. Med Educ 1999;33:447-54.

[28] Wigersma L, van Berkestijn LG, Giesen P. Eindtermen huisartsopleiding 2000. Universitair Medisch Centrum Utrecht; 2000. Ref Type: Report.

[29] Lincoln YS, Guba EG. Naturalistic inquiry. Beverly Hills, CA: Sage; 1985.

[30] Salmon P, Dowrick CF, Ring A, Humphris GM. Voiced but unheard agendas: qualitative analysis of the psychosocial cues that patients with unexplained symptoms present to general practitioners. Br J Gen Pract 2004;54:171-6.

[31] Arborelius E, Bremberg S. What can doctors do to achieve a successful consultation? Videotaped interviews analysed by the 'consultation map' method. Fam Pract 1992;9:61-6.

[32] Nettleton S, Watt I, O'Malley L, Duffey P. Understanding the narratives of people who live with medically unexplained illness. Patient Educ Couns 2005;56:205-10.

[33] Frank AW. The wounded storyteller; body, illness, and ethics. Chicago/London: The University of Chicago Press; 1995.

[34] Nettleton S. Enigmatic illness: narratives of patients who live with medically unexplained symptoms. Social Theory Health 2004;2:47-66.

[35] McWhinney IR. A textbook of family medicine. New York/Oxford: Oxford University Press; 1989.

[36] Inui TS, Carter WB. Problems and prospects for health services research on provider-patient communication. Med Care 1985;23:521-38.

[37] Coleman T. Using video-recorded consultations for research in primary care: advantages and limitations. Fam Pract 2000;17:422-7.

[38] Borkan JM. Mixed methods studies: a foundation for primary care research. Ann Fam Med 2004;2:4-6.

[39] Frankel RM. From sentence to sequence: understanding the medical encounter through microinteractional analysis. Discourse Process 1984;7: 135-70.

\section{TABLES}

Table 1

Codes appearing from utterances of the participants of the persistent MUS consultations.

\begin{tabular}{l}
\hline Codes \\
\hline Story of the patient (narrative) \\
Symptoms \\
Patients' beliefs and expectations \\
Patients' fears and concerns \\
Consequences on patients' daily activities and illness behavior \\
Consequences on patients' social environment \\
Explanation \\
\hline
\end{tabular}


Olde Hartman, T.C., Rijswijk, E. van, Dulmen, S. van, Weel-Baumgarten, E. van, Lucassen, P.L.B.J., Weel, C. van. How patients and family physicians communicate about persistent medically unexplained symptoms: a qualitative study of video-recorded consultations. Patient Education and Counseling: 2013, 90(30), 354-360

Table 2

Stages of the consultation.

Story of the patient (narrative)

The retelling, in patients' own words, of a series of unfolding events regarding the symptoms, representing the patient individual viewpoint.

Agenda setting

Agreement (between patient and FP) of the issues which should be discussed during the consultation.

Discussion/exploration of the symptoms

Discussion and exploration of the characteristics of the symptoms (nature, location, intensity, frequency and duration).

Discussion/exploring of the reason for encounter (RFE)

Discussion and exploration of the reason for encounter, including the patients' expectations regarding the actions of the doctor.

Discussion/exploration of patients' beliefs and concerns ${ }^{\mathrm{a}}$

Discussion and exploration of patients' ideas regarding the symptoms, such as patients' own explanations, symptom attribution, patients' own influences on the symptoms (self-efficacy), concerns and (negative) emotions regarding the symptoms.

Discussion/exploration of the consequences on patients' daily activities, social environment and illness behavior ${ }^{\mathrm{b}}$

Discussion and exploration of patients' behavior in response to the symptoms, the way patients cope with their symptoms, the consequences of the symptoms on patients' daily activities, the influences of the symptoms on patients' social

life, and reactions and opinions of the people in patients' surroundings.

Summarizing

FPs' summary of the symptoms, reason for encounter, beliefs, concerns and consequences of the symptoms presented during the consultation.

Physical examination

The process by which the FP performs a physical examination.

Explanation

FPs' explanation of the origin of the symptoms presented during the consultation.

Evaluation of the consultation (including making a follow-up appointment)

Evaluation of the consultation, including the question whether the consultation has been helpful, explanation and/or advices, whether the reason for encounter has been answered, and whether follow-up appointments have been made.

a Matches with the codes "patients' beliefs and expectations" and "patients' fears and concerns" that appeared from the utterances of participants of persistent MUS consultations.

b Matches with the codes "consequences on patients' daily activities and illness behavior" and "consequences on patients' social environment" that appeared from the utterances of participants of the persistent MUS consultations. 
Olde Hartman, T.C., Rijswijk, E. van, Dulmen, S. van, Weel-Baumgarten, E. van, Lucassen, P.L.B.J., Weel, C. van. How patients and family physicians communicate about persistent medically unexplained symptoms: a qualitative study of video-recorded consultations. Patient Education and Counseling: 2013, 90(30), 354-360

\section{Table 3}

The percentage of text in the transcripts spent on each of the different stages of the consultation.

\begin{tabular}{|c|c|}
\hline & $\begin{array}{l}\text { Persistent MUS patient } \\
\text { Mean }\end{array}$ \\
\hline Story of the patient (narrative) & 21.8 \\
\hline Agenda setting & Limited \\
\hline Symptom exploration & 7.9 \\
\hline \multicolumn{2}{|l|}{ Reason for encounter (RFE) } \\
\hline Initiated by the FP & 0.6 \\
\hline Initiated by the patient & 2.1 \\
\hline \multicolumn{2}{|l|}{ Patients' beliefs and concerns } \\
\hline Initiated by the FP & 4.8 \\
\hline Initiated by the patient & 13.9 \\
\hline \multicolumn{2}{|c|}{$\begin{array}{l}\text { Consequences on patients' daily activities, social environment and illness } \\
\text { behavior }\end{array}$} \\
\hline Initiated by the FP & 1.1 \\
\hline Initiated by the patient & 2.7 \\
\hline Summarizing & Limited \\
\hline Physical examination $^{a}$ & - \\
\hline Explanations & 16.8 \\
\hline Evaluation of the consultation & Limited \\
\hline Other $^{\mathrm{b}}$ & 28.3 \\
\hline \multicolumn{2}{|c|}{$\begin{array}{l}\text { a Quantifying physical examination is not possible using the proxy percentage of } \\
\text { ext spent. }\end{array}$} \\
\hline
\end{tabular}


Olde Hartman, T.C., Rijswijk, E. van, Dulmen, S. van, Weel-Baumgarten, E. van, Lucassen, P.L.B.J., Weel, C. van. How patients and family physicians communicate about persistent medically unexplained symptoms: a qualitative study of video-recorded consultations. Patient Education and Counseling: 2013, 90(30), 354-360

Fig. 1. Selection ofpersistentMUSvideoconsultations.

Excluded $(n=2725)$ according to criteria

Excluded $(\mathrm{n}=14)$ because more than one video consultation of a FP in the selection

Excluded $(n=20)$ because MUS was not the main topic of the video consultation

Total number of video consultations in Dutch National Survey of General Practice:

$$
\mathrm{n}=2784
$$
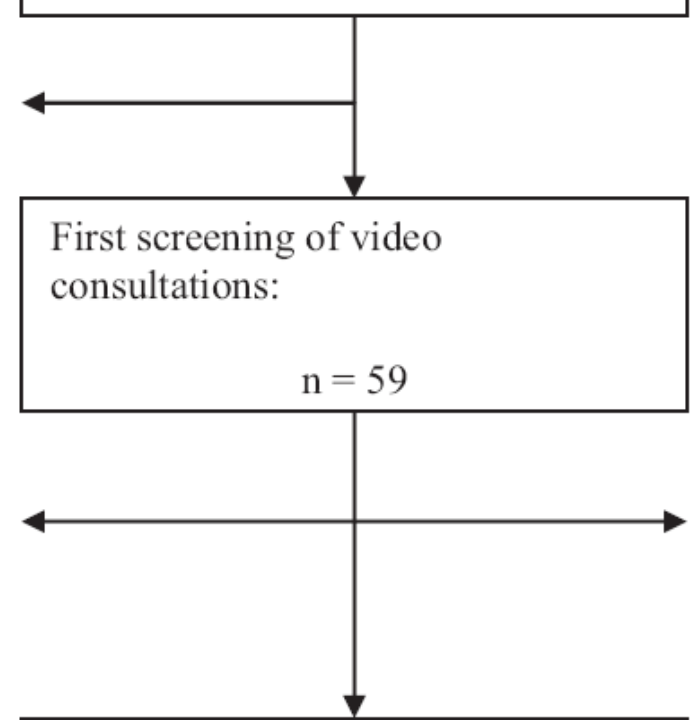

Screening of video consultation by two independent researchers:

$$
\mathrm{n}=40
$$

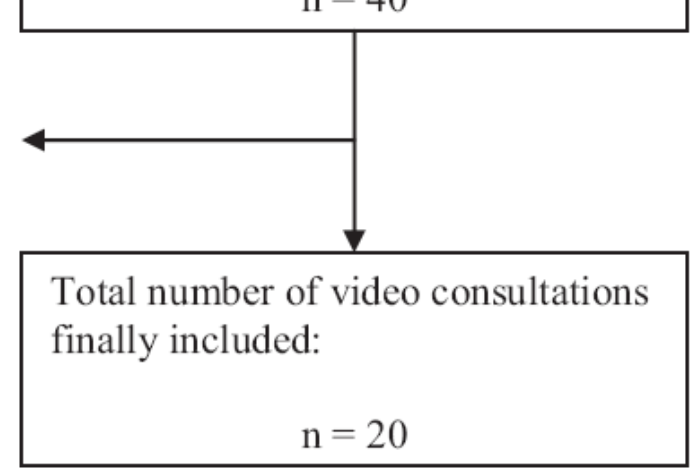

Excluded because of bad sound quality $(\mathrm{n}=$ 4) and because one of the authors (PL) was the FP in the video consultation $(\mathrm{n}=1)$ 